Anuario de Estudios Americanos, 65, 1, enero-junio, 121-152, Sevilla (España), 2008 ISSN: $0210-5810$

\title{
Los inicios del Colombinismo en la España Ilustrada
}

Juan Gil

Universidad de Sevilla

Se analiza en este artículo, sobre fuentes documentales manuscritas (las Actas de la Academia de la Historia y el Archivo de Campomanes) e impresas, el estudio de la primera colonización española en América a finales del siglo XVIII: los intentos de traducción del libro de William Robertson, la correspondencia de la Academia con Benjamin Franklin y la aparición de los libros de Juan Bautista Muñoz y Cristóbal Cladera.

Palabras Clave: Cristóbal Colón, descubrimiento de América, W. Robertson, B. Franklin, chevalier Luis-Guillermo Otto, J. B. Muñoz y C. Cladera.

In this article is anylized, on the base of both manuscript (The Acts of the Academy of History and the Campomanes' Archive) and printed sources, the study done at the end of the XVIII century about the first colonization of America: the attempts of translating W. Robertson's book, the correspondence of the Academy of History with Benjamin Framklin and the publication of the books of J. B. Muñoz and C. Cladera.

KEYwords: Christopher Columbus, Discovery of America, W. Robertson, B. Franklin, chevalier LouisGuillaume Otto, J. B. Muñoz and C. Cladera.

A David y Sasha Cook

En las postrimerías del siglo XVIII comenzó a despertarse un vivo interés por la figura de Colón, un personaje histórico que, hasta aquel momento, se había ido sumiendo paulatinamente en las brumas del olvido. En cierto modo, la resurrección espiritual del primer almirante de las Indias entraba dentro de la lógica. Tanto la dominación inglesa como la española en el Nuevo Mundo tocaban a su fin; y es achaque común del hombre que en los momentos de ocaso se rememoren las circunstancias del orto, como queriendo buscar en los orígenes las causas - y quizá los remedios- de las complicaciones y angustias del presente. De esta suerte renació con nuevos bríos en América y en Europa el cultivo de la primera historia colonial como llave para entender su época y aun sus propias circunstancias. En España, sin embargo, no ocurrió el mismo fenómeno. Metida en su caparazón, la vieja metrópoli prefirió orillar tanto los problemas que planteaban 
las colonias americanas como las soluciones que le proponían sus cabezas más preclaras, quizás en la idea de que era peor menear las cosas y con la vana esperanza de que los conflictos se arreglaran por sí solos.

Un caso paradigmático, creo, lo constituye el silencio que sobre Colón y sus viajes guardó durante mucho tiempo la Real Academia de la Historia, fundada en Madrid. A pesar de ser por real decreto Cronista oficial de Indias desde el 5 de octubre de 1744 y perpetuo desde el 18 de octubre de $1755,{ }^{1}$ la docta Corporación vivió como en un aparente letargo en lo que tocaba al cumplimiento de su obligación para con los primeros anales ultramarinos. Sólo se avivó su interés por el Descubrimiento cuando fuertes aldabonazos de fuera llamaron a su puerta, y aun esa atención se prestó como a desgana. A los académicos de entonces, entre los que había sabios ilustres, parecía agradarles más las "medallas", como a la sazón se decía, que los papeles de Indias: una y otra vez se discutieron en sus sesiones cuestiones relativas a la Numismática española de todas las épocas, y muy pocas veces se debatieron asuntos del Nuevo Mundo. La delicada situación política de las colonias exigía discreción, sin duda alguna, pero no un mutismo casi absoluto por parte de sus elites rectoras.

Además de otros materiales, he repasado para escribir este artículo las Actas de las sesiones de la Academia de la Historia desde la aparición del libro de W. Robertson hasta la entrada de J. B. Muñoz en la Corporación, ${ }^{2}$ dos fechas significativas que marcaron un hito en los estudios americanistas. En ellas se comprueba cómo la atonía de la Casa se vio sacudida sólo por los impulsos venidos del extranjero. Hasta el nombramiento de Muñoz como académico numerario le vino impuesto por decreto. Pero atendamos ya a los hechos.

\section{Un proyecto frustrado: la traducción de la Historia de América de W. Robertson}

En 1777 apareció la History of America del gran historiador escocés William Robertson (1721-1793). ${ }^{3}$ El volumen llegó casi de inmediato a

1 Su dotación por tal concepto fue de 60.000 reales al año.

2 Quiero agradecer muy de veras a la Real Academia de la Historia, y muy en especial a su secretario perpetuo, don Eloy Benito, las facilidades que me fueron dadas para consultar las Actas de sus sesiones, agradecimiento que hago extensivo a las bibliotecarias de la Fundación Universitaria Española por haberme abierto las puertas del Archivo de Campomanes.

3 Sobre su figura véase T.S., Dictionary of National Biography, Oxford University Press, Oxford (1885-1909), XVI, págs. 1311-1316. 
manos de los eruditos españoles y más en concreto de Ramón de Guevara Vasconcelos, un doctor en Teología nacido en Ceuta que, nombrado académico numerario de la Historia el 11 de agosto de 1775 y supernumerario el 11 de abril de 1777, creyó haber encontrado la ocasión pintiparada de dar a conocer sus saberes y alardear de su conocimiento del inglés, poniendo en castellano algunos trozos de la misma para informar a la Corporación de la importante novedad que había surgido en el campo del americanismo. ${ }^{4} \mathrm{El} 8$ de agosto de 1777 Guevara leyó algunos pasajes de su traducción en medio de la complacencia general y, dada la relevancia de la obra, la Corporación acordó nombrar a Robertson académico correspondiente. ${ }^{5}$

A partir de entonces, la History romanzada de Robertson comenzó a ser muy citada en las sesiones académicas, pues también se tomó corporativamente la decisión de traducir esta obra, ilustrándola con notas que aclarasen algunos acontecimientos con mayor profundidad o lo hiciesen desde un punto de vista menos inglés (o, para hablar con más propiedad, menos escocés).

La primera duda que se debatió el 24 de octubre de 1777 no tuvo que ver con Colón en realidad, sino con la famosa historia del piloto anónimo, rechazada por Robertson y presumiblemente aceptada por los españoles por aquello de la negra honrilla:

El señor Sedano leyó una nota de la Historia de América del Señor Robertson sobre la especie del piloto español que se dice haver descubierto las Indias antes que Colón, corriendo tormenta. Con este motivo leyó el Señor Guevara Vasconcelos la crítica que hace el señor Robertson de esta noticia. Y Su Ilustrísima [el Director] ordenó que las reflexiones del Señor Sedano se pasen a los Señores encargados de ilustrar con notas la traducción de dicha obra para que las examinen consultando los originales, y hagan de ella el uso conveniente.

La discusión se prolongó en la sesión del 14 de noviembre de 1777:

El Señor Guevara Vasconcelos concluyó la lectura de la memoria que empezó a leer en la Junta anterior sobre las observaciones hechas por el Señor Sedano, leídas en la Junta de 24 del pasado, acerca del primero descubridor de las Indias. Y se acordó se

4 En la Fundación Universitaria Española, Archivo del Conde de Campomanes, 4-8, se encuentra un Examen de la Historia de America escrita por el Doctor Guillermo Robertson, Rector de la Vniversidad de Edinburgo y Cronista de Escocia, traducida del Yngles por Don Ramón de Guevara, de la Real Academia de la Historia. Consta de 125 hojas, en las que Guevara dio "una noticia general de toda la obra, notando los descuidos y equivocaciones intolerables del Autor, haciendo al fin de cada Libro una breve reflexión". Es probablemente el informe leído en resumen ante la Academia.

5 Algunos de estos detalles fueron dados a conocer por Fernández Duro, Cesáreo: "Don Juan Bautista Muñoz. Censura por la Academia de la Historia de su Historia del Nuevo Mundo", Boletín de la Real Academia de la Historia, 42, Madrid, 1903, págs. 5-59, págs. 5ss. 
pase a los Señores encargados de ilustrar con notas la traducción de la Historia de América escrita en idioma inglés por el Señor Robertson, a los que se mandaron entregar las otras oraciones del Señor Sedano, para que de todo hagan el uso conveniente.

La lectura de la traducción de Guevara siguió amenizando las sesiones de la Academia. El 12 de diciembre de 1777:

El Señor Guevara Vasconcelos continuó leyendo su traducción de la Historia de América, y llegó hasta la pag. [en blanco] y \$ [en blanco] cuyo epígrafe dice: Tramas contra Colón en la Corte de España, y se concluyó la Junta.

El 19 de diciembre de 1777 acordó la Academia proponer al rey la publicación de la History de Robertson traducida al castellano, una obra que, por haber sido escrita por un sabio extranjero, se presumía que habría de tener más crédito y aceptación en el mundo literario que si hubiese salido de la pluma de un español. En pro del proyecto se adujeron, además, otras razones de peso: si el texto de Guevara "no cede ni en elegancia ni en la pureza al estilo del original inglés", la revisión prevista tendría sobre el original la ventaja de que algunos errores cometidos por Robertson podrían ser corregidos por una comisión, compuesta por Ignacio Hermosilla, Antonio Mateos Murillo y el propio Ramón de Guevara; a cargo del primero estaría el estudio de los documentos guardados en la Secretaría del Archivo de Indias; del segundo, el examen de las noticias que hubiese en las dos Secretarías del Consejo de Indias, y del tercero, la revisión de la Contaduría. La decisión académica fue comunicada el 27 de diciembre al ministro Joseph de Gálvez por su Director, D. Pedro Rodríguez (17231803), conde de Campomanes. Otra carta del mismo tenor fue despachada el 2 de enero de 1778 a don Miguel de Sanmartín Cueto.

Mientras continuaba la lectura de la obra, esta vez en una junta más reducida, el 2 de enero de 1778 la Academia pidió a Gálvez y al mayor Manuel de Ayala que facilitasen a Murillo los documentos que fuesen menester para poner al día la obra de Robertson. ${ }^{6}$ Los comisionados empe-

6 Así consta en las actas de dos sesiones:

2 de enero de 1778: "Leí el acuerdo de la Junta establecida para que en ella se continúe la lectura de la versión castellana de la Historia del Descubrimiento de América escrita por el Señor Robertson; y habiendo hecho presentes que el $\mathrm{P}^{\mathrm{e}} \mathrm{M}$. Concepción no havía concurrido por hallarse indispuesto, nombró S. I. al Señor Murillo para que asistiese también a ellas, y resolvió que dicha lectura se continuase también en los viernes de cada semana, separándose de la Junta ordinaria los Señores que componen esta particular". 
zaron a moverse. En la sesión del 23 de enero de 1778 Guevara informó que, en cumplimiento del cometido que le había encargado la Academia, había recabado información ante don Francisco Machado, ministro y contador general del Real y Supremo Consejo de las Indias, "que le ofreció facilitar quanto se pudiese encontrar en aquella oficina" para ilustrar la traducción. Los mismos trámites dijo haber hecho Murillo, en la sesión del 30 de enero, ante M. de Ayala, "por lo perteneciente a la Secretaría del Despacho Universal de Indias"; M. de Sanmartín Cueto, "por lo perteneciente al Perú", y A. Ventura de Taranco, secretario de la Nueva España. No menos halagüeños informes dieron Guevara y Murillo el 6 y el 13 de febrero y el 13 y el 20 de marzo (en estos tres últimos días presentando ya copias de diversos viajes sacadas de la Secretaría del Despacho). El 20 de febrero se reiteró la importancia de que la traducción se pusiese "con la mayor brevedad en estado de publicarse", de suerte que el 13 de marzo se remitió ya a Josef de Gálvez "la traducción del tomo $1^{\circ}$ de esta obra [de Robertson]... y la mitad del Prólogo relativo a las concesiones Pontificias por lo tocante a las conquistas". La junta encargada del examen de la Historia de América declaró el 27 de marzo que había concluido la lectura de la obra; su informe fue leído el 10 de abril. No por ello cesó el acopio de manuscritos: a la Academia llegaron copias de las cartas de Cortés conservadas en Viena o en poder de particulares (10 de julio; cf. 14 de agosto, 28 de agosto, 4 de septiembre, 8 de enero de 1779, 5 de marzo, 13 de agosto, 22 de septiembre de 1780), diarios de viajes ( 24 de julio, 30 de octubre, 11 de diciembre), etc.

La idea de verse encumbrado por una Academia extranjera satisfizo a Robertson, que con este motivo escribió una carta al director expresando su complacencia por la distinción de que había sido objeto, poniendo de relieve sus más sinceros deseos de colaborar con los revisores de su obra y manifestando su "celo por el honor de una nación que yo he respetado más que algunos otros escritores estrangeros, porque he procurado conocerla mejor". La epístola fue leída por R. Guevara el 27 de febrero y transcrita en las actas y contestada por Campomanes en la sesión del 6 de marzo.

Tan prolongados esfuerzos no dieron los frutos apetecidos, y no por culpa de los académicos. El 8 de enero de 1779 el director, Campomanes,

9 de enero de 1778: "Informé a los Académicos que en el día cinco del corriente se havía continuado la lectura de la versión castellana de la Historia del Descubrimiento de América escrita por el Señor Robertson, y se havía resuelto tener una Junta a presencia del Señor Director. Y Su Ilustrísima señaló para ella la mañana del día once, para que concurriesen a su posada los individuos que la componen". 
informó "de lo ocurrido respecto a la traducción..., ofreciendo pasar a la Secretaría los papeles respectivos a este asumpto que se hallen en su poder para que se guarden con las reservas devidas, no haviendo en el día nada que hacer en este asunto, pues por la vía reservada se han tomado las providencias que han parecido oportunas a las presentes circunstancias de los negocios generales de Europa, encargando a los concurrentes el secreto que pide la materia, de que quedó enterada la Juncta". La proyectada guerra con Inglaterra había arruinado el proyecto en cierne: en julio los españoles intentaron una vez más recobrar Gibraltar por la fuerza de las armas. ${ }^{7}$

La relación de la Academia con Robertson, sin embargo, se prolongó un poco más. Inflamados los ánimos por la contienda bélica, durante los días 2 y 3 de febrero de 1779 se declaró en Edimburgo un "alboroto contra los católicos". Robertson, que había logrado gallardamente que se rechazase en la Asamblea General una propuesta de ley contra la amnistía concedida a los católicos escoceses, fue víctima de insultos y ultrajes a causa de su valiente actitud: hasta su casa en Edinburgo fue atacada por el populacho. Juan Geddes, rector del Colegio de San Ambrosio de Escoceses en Valladolid, pidió a la Academia que expresase su gratitud al benemérito historiador por haber salido en defensa de la minoría católica; y así lo hizo la Corporación el 11 y 18 de junio de ese año. ${ }^{8}$

\section{Regalo de un libro colombino. Otros dictámenes de la Academia sobre obras de tema americano}

El 13 de noviembre de 1778 la Academia recibió un regalo precioso del marqués de Monasterio: las Annotationes Julii Salinerii jure Consulti Savonensis ad Cor. Tacitum, Genuae, apud Josephum Pavonem, 1602, superiorum permissu, un libro raro que contiene valiosa información sobre

7 Según Manuel Ballesteros Beretta, en sus artículos "Don Juan Bautista Muñoz. Dos facetas científicas" y "Juan Bautista Muñoz: La Historia del Nuevo Mundo", en Revista de Indias, Año II, 3, Madrid, 1941, págs. 5-37, págs. 12-13 y Año III, 10, Madrid, 1942, págs. 589-660, pág. 639, fue el nombramiento de Muñoz la causa principal de que el rey desechara publicar la History de Robertson traducida por Guevara.

8 Sobre estos sucesos Guevara presentó el 30 de julio un impreso en inglés sin dar el título del mismo. Las mismas violentas manifestaciones contra los católicos tuvieron lugar en Londres en 1780 , llegando entonces a ser quemada la casa de lord Mansfield: quien tal hace, que tal pague, comentó irónico B. Franklin al enterarse de la noticia (The Writings of Benjamin Franklin, Collected and Edited with a Life and Introduction by Albert Henry Smith [en adelante WBF], Haskell House Publishers Ltd., New York, 1970, VIII, págs. 99, 106 y 204). 
la estancia de Colón en Saona así como sobre la familia de Miguel de Cúneo, el aventurero y cronista que pasó a las Indias en 1493 y volvió a Europa en 1495. "Se acordó tenerlo presente en los asuntos de que trata, respectivos a la genealogía de Don Christóval Colón descubridor y primer Almirante de las Indias Occidentales; y que para ello no se saque de la Bibliotheca de la Academia".

En la sesión del 4 de agosto de 1780 se vio un tomo manuscrito escrito por don Bernardo de Estrada, intendente de Valladolid y académico honorario, sobre el Descubrimiento e Historia de las Indias. La Academia confió su examen a los señores Marín y Ramón de Guevara (este último debió de declinar el encargo, a juzgar por su inmediata sustitución por Jovellanos). El 9 de marzo siguiente Jovellanos leyó el informe que habían redactado Marín y él en comandita, en el que se exponían los graves fallos que ambos habían encontrado en el volumen: "La Academia, en su vista, acordó que, según el estado de esta obra y falta de acotaciones para calificar los hechos y de la crítica que deve hacerse de ellos, no parece conveniente use del título de académico, lo que se le prevenga verbalmente al $\mathrm{Sr}$. Estrada por el presente secretario [Joseph Miguel de Flores], debolviéndole su manuscrito y reservando en la Secretaría las censuras". Presionó el autor desde el Consejo de Indias, donde probablemente contaba con fuertes valedores, y quizá incluso con el apoyo de Sanmartín Cueto, de suerte que se remitió el nuevo manuscrito a la Corporación. Y así, el 21 de noviembre de 1783, la Academia encargó un nuevo examen del Compendio histórico de los Descubrimientos del Nuevo Mundo y sucesos de él hasta el año 1782 a Jovellanos y a Miranda. El 25 de junio Jovellanos, aunque halló la obra "no poco diferente de como estava quando la examinó con el difunto señor Marín el año de 1761", le formuló las mismas objeciones: "el autor en este medio tiempo, más que a corregir su obra de los defectos en que havía incurrido, parece se ha dedicado a aumentarla y adornarla, con lo qual este compendio, que constava de 527 fojas útiles, sube a el número de 679; que en nada ha mejorado el orden, la exactitud, la crítica ni el estilo de su obra". Consiguientemente, la Academia dictaminó "no ver conveniente su publicación en el estado en que se halla".

El 11 de enero de 1782 Campany leyó el juicio que le había merecido la lectura del Discurso, escrito por Mr. Segnier y traducido por el fr. Thomas Hemar [Hémard], contra la Historia philosophica de los establecimientos de los europeos en las dos Yndias [Histoire philosophique et politique des établissements et du commerce des européens dans les deux 
Indes] de Guillaume Thomas Raynal (Amsterdam, 1770).9 A su entender, la obra contenía algunas oscuridades, aunque no atentaba contra la religión. De todas maneras, y a pesar de la ortodoxia de su contenido, el dictamen de Campany fue negativo: el crítico "no le comprende de ninguna utilidad en lengua castellana". Visto su parecer, la Academia determinó que el libro no saliese a la luz pública, punto menos que inútil en un país como España, "donde es conocida de mui pocos la obra condenada [la del abate Raynal]".

El 22 de agosto de 1783 fue sometido al dictamen académico el primer tomo de la Historia política de los Establecimientos Ultramarinos de las Naciones Europeas, escrita por Eduardo Malo de Luque. Según Jovellanos, que emitió su informe el 26 de setiembre, la Historia estaba tomada de la obra del padre Raynal, condenada en España por el Santo Oficio, si bien se habían corregido y enmendado sus errores, de suerte que nada había en ella contrario a la religión. La Academia decidió que se devolviera la obra al Consejo y, para quitar el último escrúpulo, estimó prudente que fuera sometida a la censura del juez eclesiástico ordinario antes de concederle la licencia de impresión. El 12 de marzo de 1784 la Academia volvió a confiar al juicio de Jovellanos la crítica del segundo volumen. El 28 de mayo siguiente Jovellanos lo consideró "digno de ver la luz pública por su elegancia y no contener cosa contraria a las leyes y buenas costumbres" y la Academia se conformó con su parecer. Era lógico. Bajo el inocente anagrama "Eduardo Malo de Luque" se escondía en realidad Pedro Francisco Luján y Suárez de Góngora, un curtido diplomático que había visto recompensados sus servicios en el extranjero con el nombramiento de duque de Almodóvar en 1779. Por tanto, la Historia política de los establecimientos ultramarinos de las naciones europeas, en cinco volúmenes, vio sin tardanza la luz en la madrileña imprenta de Antonio Sancha de 1784 a 1790. Qué era en realidad esa historia lo confesó sin tapujos su propio "autor" en el prólogo:

No tengo tanto amor propio, que me impida confesar sin rubor, que el inmenso trabajo de esta utilisima obra se le debe à una pluma estrangera; pero una pluma, que teñida muchas veces en sangre dañada, es una mortal ponzoña. No ha sido corto mi trabajo, para purificarla de sus venenosos efluvios; y para corregirla de aquel orgullo, y elacion, que no podian menos de contener los pensamientos de un hombre que se llama à si mismo el defensor de la humanidad, de la verdad, de la libertad. Las personas instruidas saben muy bien lo que significa aquel vano atributo en estos tiempos. ${ }^{10}$

9 Hay una selección moderna hecha por Gabriel Esquer, PUF, París, 1951.

10 Vol. I, pág. V. 
El voluminoso estudio, espléndidamente editado, no es más que la muy interesante Histoire del abate Raynal corregida, sin citarlo, ${ }^{11}$ in usum piorum lectorum Hispaniae. ${ }^{12} \mathrm{Y}$ ello por propia confesión de parte. No había fuste ni para escribir una historia de cuño propio. Por otra parte, en esta obra no había cabida para América, pues únicamente se contemplaron en ella los asentamientos de los europeos en Asia $; i^{13}$ Colón fue despachado con una breve mención en V, págs.114-116, mención que no por breve dejó de dar crédito a la historia del piloto anónimo.

\section{Benjamin Franklin y la Academia de la Historia}

Ha llegado el momento de hablar de una figura en verdad egregia, Benjamin Franklin, ${ }^{14}$ un hombre inmensamente venerado tanto en la

11 Siempre sustituye su nombre por perífrasis: "el Autor que sigo" (II, pág. 39). "Ha sido, y aún es de cierto modo, la guia ó modelo en el todo de esta obra un autor francés. No se le sigue ciegamente: se le toman algunas noticias: se abraza su metodo: se omite, o se contradice quanto parece justo desaprobar ó suprimir: se añade quanto se juzga conducente á la instruccion y recreo del lector; y se forma una conveniente continuaion hasta el mismo año en que se entrega cada tomo" (V, pág. V). El nombre del abate Raynal sólo aparece en V, págs. VIII y 144.

12 He aquí algunas perlas: "Francia... es vecina y natural aliada de la España: deben considerarse como pasageras las varias diferencias que suelen o pueden ocurrir de Gabinete a Gabinete sobre ciertos peculiares intereses de Nación á Nación en algunos artículos ó asuntos: pero es de un comun interes y conveniencia recíproca de ambas, no solo la buena y decorosa armonía; sino tambien la íntima correspondencia y union, confirmando el célebre dicho de Luis XIV. de que ya no había Pirineos" (II, pág. VI). "Siempre la España fue Monarquía, con solo aquellas variaciones proprias de sus diversas y respectivas circunstancias; este ha sido y es el genio, complexîon, y caracter de la Nacion; no puede sufrir incensar la pluralidad de Deidades, hablando humanamente; la unidad de una sola es la que la lleva y ocupa toda sus atenciones, es á la que dirige su veneracion; al modo que es una sola la Divina, á quien rinde sus adoraciones, tributa sus cultos" (III, pág. VI). El meridiano de Greenwich fue sustituido por el de Tenerife, "el mas propio para nuestra Nación” (IV, pág. VI). "La Nación Española debe reputarse por lamas i constantemente culta, desde los tiempos antiguos, hasta los modernos; sus atrasos en estos últimos, en quanto a las ciencias llamadas exâctas, se deben considerar como un parentesis" (V, nota de pág. 114). Curiosamente, la manera de proceder del duque de Almodóvar le pareció de perlas a Jacobo Antillano Nuero (sin duda un pseudónimo) en el artículo publicado en el Espíritu de los mejores diarios literarios que se publican en Europa (la revista de C. Cladera, personaje del que hablaremos más tarde), págs. 559-560: gracias al duque, "desaparece el Autor impío" y queda impoluta la doctrina que imparte.

13 Al tratar de Filipinas añadió el autor datos de su cosecha, sobre todo al exponer la toma de Manila por los ingleses y la creación de la Compañía de Filipinas. Las fuentes del último apartado son muy diversas: el informe presentado el 18 de noviembre de 1788 por la Dirección de Manila al capitán general (V, pág. 348), varios informes de los directores de la Compañía del 10 de julio de 1789 (V, págs. 364ss.) y la memoria presentada a la Sociedad Patriótica en 1783 (V, pág. 374), entre otras.

14 Sobre la figura de B. Franklin en relación con los problemas aquí tratados me remito al libro coordinado por Anes, Gonzalo, y Garrigues, Eduardo: La Ilustración española en la independencia de los Estados Unidos: Benjamín Franklin, Madrid-Barcelona, 2007 y a la bibliografía allí citada. 
América hispana $\mathrm{a}^{15}$ como en la propia metrópoli. Entre sus fervientes admiradores se contó hasta un hijo de Carlos III, el infante don Gabriel de Borbón, que, sirviéndose de los oficios del embajador español, hizo llegar en 1775 a Franklin su traducción de Salustio, impresa espléndidamente por Ibarra en 1772.16 Por esta razón, una vez rotas las hostilidades con Inglaterra, el Congreso de los Estados Unidos decidió muy sabiamente en 1777 que Franklin trasladara su acción diplomática de Francia a España, en la convicción de que allí su labor se vería coronada más fácilmente por el éxito al tener en la corte un valedor de primerísima calidad. ${ }^{17}$ No fue así, sin embargo, y ello en buena parte por propia decisión del interesado, que desoyó el nombramiento oficial y prefirió quedarse en Francia: a decir verdad, la elección más certera y apropiada para la defensa de los intereses de los nacientes Estados Unidos.

España era todavía una potencia colonial muy considerable, y más en América, por más que su diplomacia dependiera de las directrices de Francia en muchos frentes, sobre todo en cuanto concernía a la política a seguir con Inglaterra. Por tanto, aun sin discutir el acierto de su permanencia en París, hubiera sido de esperar que la negociación con España hubiese despertado más interés en un hombre, como Franklin, que sabía algo de

15 Así lo demuestra el hecho de que el sabio jesuita mexicano Francisco Javier Clavigero (+ 1787) escribiese en latín un compendio de filosofía en el que, además de tratar de los antiguos griegos, analizó la doctrina de los pensadores modernos desde Francis Bacon y Descartes hasta Franklin (ad Americanum Franklinium, cf. Joannis Aloysii Maneiri Veracrucencis de vitis aliquot Mexicanorum aliorumque qui sive virtute, sive litteris Mexici inprimis floruerunt, Bolonia, 1791, III, pág. 51). En las repetidas visitas que Echevarría y Belgrano rindieron en La Asunción al despacho del tétrico dictador Dr. Francia (1811), encontraron "colgado frente a su mesa el retrato de Franklin, lo que debía hacerle creer que aquel era el sublime modelo que se proponia imitar" (Mitre, Bartolomé: Historia de Belgrano y de la independencia argentina, Universidad de Buenos Aires, Buenos Aires, 1950, pág. 161 a). Pero el hecho de que los nombres de Franklin y Washington fuesen bien conocidos en los círculos criollos no quiere decir que hubiese contactos directos entre los Estados Unidos e Hispanoamérica: sólo unos pocos, como Miranda y Bolívar, visitaron Estados Unidos antes de 1810, según señala con razón Charles C. Griffin (The United States and the Disruption onf the Spanish Empire. 1810-1822, Columbia University Press, New York, 1937, págs. 56-57).

16 Al recibir el libro en Filadelfia, Franklin dio las gracias al infante el 12 de diciembre de 1775 (WBF VI, págs. 436-437). Véase asimismo la clara alusión al infante en la carta a Arthur Lee (Passy, 21 de marzo de 1777: ibídem, VII, pág. 32). Utilizo esta edición porque en la más cuidada, preparada por L. W. Labaree y B. B. Oberg (The Papers of Benjamin Franklin, Yale University Press, New Haven, 1964 [en adelante TPBJ]), las cartas sólo llegan hasta febrero de 1779.

17 Carta al conde de Aranda (Passy, 7 de abril de 1777: WBF VII, págs. 40-41): "I left in your Excellency's Hands, to be communicated, if you please, to your Court, a Duplicate of the Commission from Congress, appointing me to go to Spain as their Minister Plenipotentiary. But, as I understand that the Receiving such a Minister is not at present thought convenient, and I am sure the Congress would have nothing done that might incommode in the least a Court they so much respect, I shall therefore postpone that Journey till Circumstances may make it more suitable". 
español ${ }^{18}$ y que, siempre curioso y atento a todo, estuvo al tanto más tarde, muy probablemente a través de W. Carmichael, de la reedición de la Bibliotheca Hispana Nova de Nicolás Antonio (Madrid, 1783). ${ }^{19}$ También el conde de Aranda, don Pedro Pablo Abarca de Bolea (1718-1799), causó a Franklin buena impresión durante la entrevista que ambos mantuvieron en París en $1777 .{ }^{20}$ Todo, pues, parecía concurrir para que se hubiese producido un buen entendimiento por ambas partes.

Sin embargo, y a pesar de estos amistosos encuentros individuales, España en su conjunto constituyó siempre un país extraño y desdibujado para el sabio norteamericano que, muy contrariamente a la común libertad de su juicio, se dejó llevar en este caso por lo que decían los tópicos al uso sobre la tierra y sus habitantes. He aquí un caso muy ilustrativo: en 1764 alabó Franklin el honor de los españoles, capaces de no apresar como botín de guerra un barco enemigo —el Elizabeth — arrastrado en 1746 por la tempestad al puerto de La Habana; pero esta profunda estima del honor era, a juicio de Franklin, una herencia que habían dejado los musulmanes a los españoles. ${ }^{21} \mathrm{Y}$ aun hay más: si aquí aparecen citados los españoles, lo son entre otros pueblos más o menos salvajes —sarracenos, negros de Guinea, indios americanos- y ello con el único fin de contrastar la pureza inquebrantable de su lealtad, inimaginable en pueblos de escasa cultura, con la traidora y brutal sevicia de los civilizados blancos de Lancaster, que no pararon hasta aniquilar a sangre fría a los míseros restos de los indios conestogoe (1764). Salta a la vista que en este discurso intelectual subyace una nebulosa idea de España, un país que, envuelto en un acentuado ropaje oriental, no hace sino heredar las supuestas virtudes (el honor) y los no menos imaginarios defectos (la crueldad) inherentes al Islam: los mismos tópicos que, con mucho más conocimiento, profundidad y simpatía, habría de desarrollar corriendo el tiempo Washington Irving.

A Franklin, sorprendentemente, le fue ajena la realidad de la política española. Si la transcripción de sus cartas no engaña, no acabó de enterar-

18 "I read Spanish a little" (carta a W. Carmichael [Passy, 27 de enero de 1781: ibídem, VIII, pág. 205]).

19 Supuso Franklin erróneamente que estaba escrita en español (carta a W. Carmichael [Passy, 27 de enero de 1781: ibídem, VIII, pág. 205]). No llegó a comprar la obra porque su precio le pareció excesivo (carta a W. Carmichael [Passy, 12 de abril de 1781: ibídem, VIII, pág. 237]).

20 Cf. ibídem, VII, pág. 9.

21 "The Spaniards caught from the Moors this Punto of Honour, the Effects of which remain, in a great Degree, to this day" (Narrative of the Late Massacres in Lancaster Country: ibídem, IV, pág. 289). 
se de que Yranda, ${ }^{22}$ a quien ya había conocido en París, se llamaba en realidad Aranda y de que no era marqués sino conde. Para el apóstol de la independencia estadounidense, España no fue sino el país de una exótica periferia que podía prestar dinero y hombres a la causa de la revolución, y poco más. La lentitud de su diplomacia, tan comprensible para un observador imparcial, lo exasperaba. ${ }^{23}$ Tampoco pasó nunca por su cabeza que España pudiera reunir los atractivos culturales que lo deleitaban en Francia: en una de sus cartas llegó a contrastar el ambiente musical que se respiraba en París con el de Madrid, en detrimento — claro está — de la segunda capital, donde no se podría hallar ni por asomo la ardorosa pasión y los encendidos debates que se desataban en Francia entre los partidarios de Gluck y los de Puccini. ${ }^{24}$ Muy probablemente Franklin llevaba razón; pero sorprende este súbito interés por la música en un hombre que, como sabemos por confesión propia - confesión que se desliza, además, en la misma carta-, rara vez iba a la Ópera en París. ¿No suena esta afirmación desdeñosa como una inconsciente excusa por no haber aceptado el primer puesto de ministro plenipotenciario que se le había ofrecido?

Cierta prevención contra España, pues. Prevención quizá justificada por el recelo que siente todo hombre ante una cultura, un modo de ser y una religión diferentes; una España aparentemente hosca, atrasada y "supina", ${ }^{25}$ donde la Inquisición, incluso en su decadencia, todavía campaba por sus respetos. Frente a estos tétricos fantasmas de una España imaginada o real, a partir de 1776 el norteamericano se sintió muy a gusto en Francia, en cuyos estamentos sociales - tanto en el pueblo como en la elite- encontró, a la recíproca, profundo respeto, popularidad y simpatía: ${ }^{26}$ la misma

22 Cf. ibídem, VIII, págs. 51 y 53, 57, 144, 204, 240, etc. (carta a W. Carmichael [Passy, 31 de marzo de 1780]; a John Jay [Passy, 7 de abril y 2 de octubre de 1780 y 27 de enero y 12 de abril de 1781]). En TPBJ XXVIII, pág. 20 se nombra a "le Comte d'Aranda"; pero quien escribe no es Franklin, sino el francés Grand.

23 "The cry of this Nation is for us, but the Court, it is thought, views an approaching War with Reluctance" (carta al Committee of Secret Correspondence [París, 4 de enero de 1777: WBF VII, pág. 9]). En 1779 esperaba Franklin que España declarase la guerra a Inglaterra (cartas a John Jay [Passy, 2 de junio y 4 de octubre de 1779: ibídem, VII, pág. 342 y 383]). Pero del "delay" de la Corte española se quejó ya en carta al conde de Vergennes (Passy, 13 de febrero de 1781: ibídem, VIII, pág. 210).

24 Carta a W. Carmichael (Passy, 17 de junio de 1780: ibídem, VIII, pág. 100).

25 "The supine state of Spain": la expresión es de Thomas Digges en carta a Franklin (31 de enero de 1779: $P B F$, XVIII, pág. 440).

26 "The French are an amiable People to live with: They love me, and I love them", escribió al capitán Nathaniel Falconer (Passy, 28 de Julio de 1783: WBF IX, pág. 77). "La France, la Païs du monde que j'aime le plus", escribió el 19 de julio de 1785 en su despedida a Mme Helvétius (ibídem, IX, pág. 364). "'It is a country that I dearly love”, confesó el 10 de diciembre de 1578 a l'abbé Morellet (ibídem, IX, pág. 691). 
acogida sin duda que hubiera encontrado en Madrid, pero en una escala inferior para los fines que pretendía, dada la subordinación política de España a Francia. Nombrado finalmente, conforme a sus deseos, ministro plenipotenciario en la corte de Luis XVI (1778), ${ }^{27}$ Franklin derrochó a manos llenas todas sus dotes de sabio, charmeur y novel pero perfecto diplomático en consecución tenaz de su objetivo: lograr la decisiva alianza con Francia durante la guerra de Independencia estadounidense. En justa recompensa a sus brillantísimos servicios, el Congreso le renovó en 1781 su confianza: a pesar de su avanzada edad — pasaba de los 75 años- y de su propuesta de dimisión, Franklin fue elegido miembro de la comisión que negoció en París la paz con Inglaterra; los otros cuatro delegados fueron John Adams, Tomas Jefferson, Henry Laurens y John Jay. Al término de la negociación, auspiciada por la derrota de Lord Cornwallis en Yorktown (17 de octubre de 1781), los ingleses aceptaron los puntos principales que presentaron los norteamericanos relativos a la independencia de las antiguas colonias, sus fronteras y su derecho a la pesca. Con más acritud se debatió la pretendida cesión de Canadá a los Estados Unidos, que fue rechazada finalmente por los ingleses. El tratado provisional se firmó el 30 de noviembre de 1782, pero Franklin, a la espera de su ratificación definitiva, permaneció hasta 1785 en Francia, su segunda patria.

A la vista de lo dicho no sorprende que sean poco frecuentes en el epistolario de Franklin las noticias relativas a España. Por sus cartas aparecen fugazmente quiméricas propuestas, bien de los delegados estadounidenses (la promesa de ayuda a una fantástica conquista de Portugal o a la más real posesión de Pensacola), ${ }^{28}$ bien de los españoles (la no menos peregrina idea de canjear la Florida Occidental y las Bahamas por Gibraltar), ${ }^{29}$ o se trasluce el empeño de estos últimos por que los nuevos Estados quedasen encerrados dentro de los Montes Alleghani, ${ }^{30}$ una frontera cuya acep-

27 Cf. los capítulos 13-15 de la obra de Walter Isaacson, Benjamin Franklin. An American Life, Simon and Schuster, New York, 2003, págs. 325ss.

28 Carta a Arthur Lee (Passy, 21 de marzo de 1777: WBF VII, pág. 33); al conde de Aranda (Passy, 7 de abril de 1777: ibídem, VII, págs. 40-41).

29 Carta a Robert R. Livingston (Passy, 5 de diciembre de 1782: ibídem, VIII, págs. 634-35): "Spain offers for Gibraltar to restore West Florida and the Bahamas. An addition is talked of the Island of Guadaloupe, which France will cede to Spain in exchange for the other hand of the Hispaniola, and Spain to England, but England, it is said, chose rather Porto Rico. Nothing yet concluded".

30 Carta a Livingston (Passy, 8 de agosto de 1782: ibídem,VIII, págs. 579-80) "Mr. Jay will acquaint you what passes between him and the Spanish ambassador, respecting the proposed treaty with Spain. I will only mention, that my conjecture of that court's design to coop us within the Allegany Mountains is now manifested. I hope Congress will insist on the Mississippi as the boundary, and the free navigation ot the river, from which they could entirely exclude us". 
tación le parecía de todo punto inadmisible a Franklin. El 21 de enero de 1783 Franklin informó a Livingston de que se había firmado un protocolo de paz entre Inglaterra, Francia y España, en el que estos dos últimos países obtenían la paz en términos muy ventajosos para ellos. ${ }^{31}$

La relación de Franklin con los primeros ministros de los Estados Unidos en Madrid tampoco contribuyó a mejorar esa mala impresión de España. Arthur Lee se convirtió pronto en un enemigo acérrimo suyo, y John Jay —un personaje "qui passait toujours fort boutonné": así lo definió Aranda- ${ }^{32}$ chocó con la sociedad española por la estirada reserva de su trato. Las cosas mejoraron notablemente cuando llegó a la corte de Carlos III William Carmichael, ${ }^{33}$ un hombre dúctil y realista que supo introducirse con mayor tino y habilidad que sus predecesores en los diversos círculos sociales de la capital española. Fue Carmichael quien, entre otras noticias - la publicación de la Bibliotheca Hispana, como hemos dicho-, informó a Franklin de la existencia de la Sociedad de Amigos del País y de los libros que ésta iba dando a la luz. Es más: en 1781 Carmichael anunció a Franklin el envío de ejemplares tanto de esas obras de la Sociedad como de las de su director, ${ }^{34}$ buena prueba de que había entablado amistad con este último.

Llevaba a la sazón las riendas de la Sociedad de Amigos del País el propio director de la Academia de la Historia, Campomanes, un político al que atraía poderosamente la causa estadounidense, no sin que, al mismo tiempo, le inspirara fundados temores que el triunfo de la independencia contagiase con su ejemplo a las colonias españolas: cualquier hombre avisado podía prever que Francia y España habrían de pagar bien cara su ayuda a los Estados Unidos.

31 Carta a Livinsgston (Passy, 21 de enero de 1783: ibídem, IX pág. 9): “This is to inform you... that the preliminaries of peace between France, Spain, and England, were yesterday signed, and a cessation of arms agreed to by the ministers of those powers... I... hear, in general, that they are very advantageous to France and Spain".

32 Así lo comunicó Franklin a W. Carmichael (Passy, 27 de enero de 1781: WBF VIII, pág. 204).

33 Carmichael, que le presentó en 1783 a un pariente de Aranda, Simón de Casas (cf. Benjamin Franklin Papers. American Philosophical Society. Hays Calendar. Part 8, XLI, 21), aparece citado no pocas veces en el epistolario de Franklin a partir de 1780. A sus buenos oficios recurrió Franklin para salvar de las garras de la la Inquisición a James Hartwell, de Salem, detenido bajo la acusación de apóstata y puesto finalmente en libertad tras la oportuna intervención de Carmichael (WBF IX, pág. 275 y 301, 303).

34 Del retraso dio cuenta el propio Franklin en carta a Carmichael (Passy, 12 de abril de 1571 ibídem,VIII, pág. 237). 
En cualquier caso, a Campomanes hubo de halagarlo la idea de ponerse en relación con una celebridad como Franklin, uno de los principales protagonistas de "la más memorable revolución en la historia de los tiempos modernos". Es un enigma, por tanto, el retraso con que se produjo la anunciada remesa de libros, entre los cuales sin duda se encontró el famoso Tratado de la regalía de amortización (Madrid, 1765); en cuanto a las publicaciones de la Sociedad de Amigos del País, el excesivo volumen de las mismas impidió su expedición por el correo ordinario ${ }^{35}$.

La tardanza causó cierta extrañeza a Franklin, que así lo manifestó a Carmichael unos meses después. ${ }^{36}$ Pero fuera por la razón que fuese, el hecho es que esos libros prometidos con tanta antelación en 1781 no llegaron sino en 1784. Franklin, que acusó recibo de los mismos desde Passy el 5 de junio de ese año, regaló a su vez a su corresponsal un ejemplar de sus últimos tratados. La política seguida por Campomanes "reformando los antiguos hábitos, extirpando los prejuicios y promoviendo la industria" mereció todos los elogios por parte del norteamericano que, en la atenta carta que le dirigió para agradecerle su envío, no vaciló en augurar al conde un éxito mayor del esperado en sus esfuerzos, máxime cuando trabajaba sobre un material tan noble como el pueblo español: "es increíble cuánto bien puede hacer por su país un solo hombre" que haga de esta empresa su empeño exclusivo - una idea predilecta de Franklin que repitió otras veces en sus cartas - ${ }^{37}$ La felicidad de Europa, proseguía, se veía menoscabada por dos prejuicios: que el trabajo era deshonroso y que la familia se podía perpetuar gracias al mayorazgo. El segundo punto era quizá el que más dolía a Franklin, que acababa de redactar un alegato furibundo en contra de la Orden de los Cincinnati, encabezada por el propio Washington, que pretendían crear algunos republicanos de espíritu aristocrático. ${ }^{38}$ Repitió, pues, a Campomanes sus argumentos de antaño con suma brevedad, intentando ridiculizar por la vía matemática la necia inutilidad de la institución: "en sólo nueve generaciones la parte del presente propietario en el posesor futuro del mayorazgo sería sólo un 512avo, suponiendo que la

35 Nota del editor, ibídem, VIII, pág. 295.

36 Carta a W. Carmichael (Passy, 24 de agosto de 1781: ibídem,VIII, pág. 295).

37 Así lo volvió a decir en la carta a Thomas Brand Hollis (Passy, 5 de octubre de 1783: ibídem, IX, pág. 104): "it is prodigious the quantity of Good that may be done by one Man, if he will make a Business of it".

38 Carta a Mrs. Sarah Bache (Passy, 26 de enero de 1784: ibídem, IX, págs. 161ss.). La notable demostración matemática comienza en págs. 163ss. Cf. asimismo las cartas a B. Vaughan del 7 de setiembre de 1784 (ibidem, IX, pág. 270) y a G. Whatley del 23 de mayo de 1785 (ibídem,IX, pág. 336). 
fidelidad de las mujeres futuras fuese igual de cierta que la de las que hoy existen". ${ }^{39}$

Carmichael comunicó además a Campomanes que, a iniciativa de Franklin, había sido nombrado miembro correspondiente de la American Philosophical Society, sociedad cuya creación había propuesto el propio Franklin en mayo de 1743 y que había comenzado su andadura en Filadelfia en enero de $1751 .{ }^{40} \mathrm{La}$ Academia de la Historia fue informada a la vez del envío del libro y de la distinción hecha a su director en la sesión del 9 de julio de 1784 .

El Señor Don Ramón de Guevara hizo presente que el Dr. Benjamin Franklin, Ministro Plenipotenciario de los Estados Unidos de América Septentrional en la Corte de París, havía regalado un exemplar de la colección de sus obras, especialmente políticas, al Ilmo. Señor Director, escriviéndole con este motivo una carta en inglés que por orden de S. I. ha traducido el mismo Señor Guevara y que se traerá a la Academia con copia del original y la minuta de la respuesta que le diesse S. I. Añadió el propio Señor Guevara que a la carta y exemplar de las obras de Franklin acompañó el Señor Guillermo Carmichael, encargado de los negocios de los mismos Estados Unidos en esta Corte, un billete de su puño, cuya copia leí yo a la Academia, en el qual participa a S. I. que la Academia de Ciencias, establecida en Filadelphia bajo el

39 "I have received much Instruction and Pleasure in reading your excellent Writings. I wish it were in my power to make you a suitable Return of the same kind. I embrace the Opportunity, my much esteemed Friend Mrs. Carmichael affords me, of sending you a late Collection of some of my occasional Pieces, of which, if I should live to get home, I hope to publish another Edition much larger, more correct, and less unworthy of your Acceptance.

You are engaged in a great Work, reforming the ancient Habitudes, removing the Prejudices, and promoting the Industry of your Nation. You have in the Spanish People good Stuff to work upon, and by a steady Perseverance you will obtain perhaps a Success beyond your Expectation; for it is incredible the quantity of Good that may be done in a Country by a single Man, who will make a Business of it, and not suffer himself to be diverted from that Purpose by different Avocations, Studies, or Amusements.

There are two Opinions prevalent in Europe, which have mischievous Effects in diminishing national Felicity; the One, That useful Labour is dishonourable; the other, that Families may be perpetuated with Estates. In America we have neither of these Prejudices, which is a great Advantage to us. You will see our Ideas respecting the first, in a little Piece I send you, called Information to those who would remove to America. The second is mathematically demonstrable to be an Impossibility under the present Rules of Law and Religion. Since tho' the Estate may remain entire, the Family is continually dividing. For a man's Son is but half of his Family, his Grandson but a Fourth, his Great Grandson but an Eighth, the next but a Sixteenth of his Family; and, by the same Progression, in only nine Generations the present Proprietor's Part in the then Possessor of the Estate will be but a 512 ${ }^{\text {th }}$, supposing the Fidelity of all the succeeding Wives equally certain with that of those now existing: Too small a Portion, methinks, to be anxious about, so as to oppose a legal Liberty of breaking Entails and dividing Estates, which would contribute so much to the Prosperity of the Country. With great and sincere Esteem and Respect, and best Wishes for the Success of your patriotic Undertaking, I have the honour to be, Sir, \&. B. Franklin" (WBF IX, págs. 221ss.).

40 Isaacson: Benjamin Franklin..., págs. 122-123 y 147. 
título de Sociedad Filosófica, havía nombrado por uno de sus individuos al mismo Señor Ilustrísimo con las circunstancias honoríficas noticiadas en la Gaceta de Madrid de el presente mes capítulo de Londres.

Campomanes contestó a la carta de Franklin unos días más tarde, el 26 de julio de 1784, tocando brevemente en su respuesta los dos puntos capitales que había expuesto Franklin. ${ }^{41}$ En cuanto a la consideración social que merecía el trabajo, el acuerdo era total entre ambos y Campomanes sólo tuvo que insistir en que así lo hacían valer ya las leyes españolas. Por lo que tocaba al mayorazgo, en cambio, las opiniones de los dos personajes divergían de manera notable: Campomanes, más pacato - y conde al fin y al cabo-, hizo ver a su sabio amigo, un revolucionario de pro, que las circunstancias de un país como los Estados Unidos, sujeto a una constitución democrática, y la de un reino como España eran totalmente diferentes. En cualquier caso, amor con amor se paga. Así, devolviendo el honor recibido con recíproca cortesía, Campomanes puso en conocimiento de Franklin que había sido elegido por aclamación académico honorario de la Historia. Pero lo cierto es que en las actas de las sesiones no he podido encontrar ese nombramiento aceptado con tan entusiasta unanimidad. Raro olvido de una distinción que, efectivamente, fue otorgada a Franklin el 9 de julio de 1784 —el mismo día en que la Corporación tuvo noticia de la carta enviada a su director-.

Con este intercambio de elogios mutuos entre las dos celebridades no terminó la relación del estadounidense con la Academia de la Historia. Concluida su prolongada misión diplomática en París, Franklin regresó a su patria, donde una muchedumbre entusiasta le hizo un recibimiento triunfal a su entrada en Filadelfia (septiembre de 1785). Su asistencia a la redacción de la Constitución de los Estados Unidos (1787) coronó una vida fértil en realizaciones de todo tipo, presidida por el lema horaciano de la aurea mediocritas (o "happy mediocrity", como él solía decir), reinterpretado, esta vez en clave política, la virtud de la clase media. ${ }^{42}$ Pero ni los acalorados debates con que se discutieron los artículos constitucionales ni sus múltiples ocupaciones hicieron olvidar a Franklin sus vínculos con la lejana Academia española. Así lo comunicó el secretario a la docta Corporación el 30 de marzo de 1787:

41 La carta de Campomanes fue enviada a Franklin por W. Carmichael el 11 de agosto de 1784 (Benjamin Franklin Papers. American Philosophical Society. Hays Calendar. Part 8, XXXII, 80, consultado en www.amphilsoc.org/library/mole/f/franklin/hays9.htm). Está inventariada como XXXII, 63. 42 Ibídem, pág. 423. 


\section{JUAN GIL}

Leí una carta del señor Benjamin Franklin, Presidente de la Sociedad Filosófica de Filadelfia, acompañada del segundo tomo de sus Transacciones o Memorias, la qual traducida por mí dice así:

Filadelfia, 4 de Diciembre de 1786. Mui señor mío: Después de la paz ha reasumido nuestra Sociedad Filosófica sus funciones o tareas, y publicado un segundo tomo de sus Transacciones. Habiendo en él una pieza o escrito relativo a la Historia de España, discurrí podría no ser ingrato a la Academia, que me hizo el gran honor de admitirme entre sus individuos, y así lo he enviado por medio de Mr. Rendon dirigido a v.m. para uso del mismo Cuerpo ${ }^{43}$. Con mucho respeto tengo la honra etc. El más obediente y rendido servidor de Vd. Benjamin Franklin.

Señor Don Josef Miguel de Flores. ${ }^{44}$

La carta de Franklin fue respondida el 24 de mayo siguiente por Campomanes que, atareado por mil ocupaciones, no perdió sin embargo la ocasión de manifestar su satisfacción por pertenecer a la Sociedad Filosófica Americana, considerada ya como algo propio. ${ }^{45}$ La minuta de su

43 De la misma manera, en 1787 Franklin envió ejemplares de las Transactions a La Rochefoucauld, Condorcet y la Académie (WBF IX, pág. 565).

44 No se encuentra esta carta entre las publicadas por Smyth, que reproduce, en cambio, una remitida por Franklin al capitán Tomás de Ugarta y Lianes, anunciándole que se habían enviado a su barco, en peligro por los hielos flotantes, dos prácticos del puerto ("two of the Wardens of the Port"), y ello no sólo por la hospitalidad, sino por el respeto debido "to the excellent Prince, your Sovereign, and good Friend of these States" (Filadelfia, 16 de diciembre de 1786: WBF IX, págs. 551-52).

Otros tres españoles se cartearon con Franklin.

Floridablanca le escribió una carta el 9 de marzo de 1785 dando explicaciones sobre el maltrato inferido a unos estadounidenses en La Habana (Benjamin Franklin Papers. American Philosophical Society. Hays Calendar. Part 8, XXXIII 50).

Don Luis de Medina se excusó el 15 de junio de 1786 por no haber podido ir a cenar con él (ibídem, Part 9, Section I (1783-1786), XXXIV, 93).

Por fin, el ministro de España en los Estados Unidos Diego de Gardoqui le envió dos cartas desde Nueva Cork el 30 de mayo y el 19 de junio de 1787 sobre un incidente sufrido por la goleta Regla en la aduana estadounidense, solucionado aparentemente por Franklin (ibídem, Part 9, Section II (17871789), XXXV, 71; 79).

45 Una fotocopia de la carta se encuentra en la Fundación Universitaria Española, Archivo del Conde de Campomanes, 55-138 (Cejudo López, Jorge: Catálogo del Archivo del Conde de Campomanes (fondos Carmen Dorado y Rafael Gasset), FUE, Madrid, 1975, pág. 391). En cursiva van los subrayados, entre // los añadidos sobre el renglón y entre = los añadidos al margen.

Excmo. Sr. Muy Sr. mio. He recibido por mano del Sr. Guillermo Carmichel la (apreciable) /estimada/ carta de V. E. de 4 de Diciembre (del año) próximo pasado / (y) junctamente/ con (ella) el /apreciable/ título de (socio) /individuo/ de /la/ (Real) Sociedad Filosofica (de Filadelfia) Americana y el tomo $2^{\circ}$ de sus Transacciones, que contiene los estatutos (de ese) del Cuerpo, la lista de (sus) los Socios, varios /experimentos, observaciones y/ escritos (de) sobre asuntos relativos =por la mayor parte $=$ a las ciencias naturales y exactas.

Por todo (ello) (quedo) /estoy/ muy reconocido asi á V. E. como á nuestra Sociedad, en cuyas obras, que (miro en cierto modo) /me interesan ya/ como propias por la honra que me ha dispensado (en incorporar) incorporan/do/me á su gremio, voy (reconociendo) ad/virtiendo/ con indecible satisfaccion (brillar) tal juicio, sana critica é inteligencia en las respectivas facultades en que tratan, que /juzgo/ contribuirán /1v/ efectivamente (mucho) á promover /mucho/ los conocimientos útiles, =objeto del 
réplica, llena de tachaduras y adiciones puestas al margen o sobre el renglón, revela el cuidado con que fue escrita, evitando repeticiones de palabras y salvando un error inconsciente como el llamar Real a la Academia de Filadelfia - equivocación muy típica de los españoles, por otra parte- Pero Campomanes incurrió en un error fatal: al anunciar el título del libro que él, a su vez, enviaba a Franklin (el tomo primero del Diccionario español Latino y árabe del padre Cañas), declaró ingenuamente la importancia que tenía el estudio del árabe, especialmente para los españoles. No se podía haber escrito una frase más ilusa y menos diplomática: airear la herencia musulmana de España ante un anglosajón de pura cepa como era el estadounidense suponía reconocer una especie de pecado original en la génesis de la cultura española.

Pero volvamos a la Academia española de la Historia. El inesperado envío ultramarino causó en ella un pequeño revuelo doméstico. La presumible alegría de haber establecido contacto con la Sociedad Filosófica de Filadelfia se vio coartada por las incomodísimas trabas que imponía la extrema dificultad de comunicación lingüística. Los académicos, al igual que la España de entonces en general, eran más amigos de Francia que del Reino Unido, por lo que el conocimiento del inglés se restringía a un selecto puñado de personas, entre las que se encontraba nuestro ya conocido

loable instituto de = nuestra academia de Filadelfia, (igualando) y a igualarla con/siguientemente, después de la/ =renovación de sus trabajos á beneficio de la paz, con= las mas antiguas y celebres de su clase establecidas en Europa

En medio de las (tareas) /continuas ocupaciones/ del gobierno del Consejo, (que está) /puesto/ =de (algunos) /más de tres/ años a esta parte= á mi cargo, me hallará (esa Academia) ese /Cuerpo/ y su ilustre Presidente pronto siempre á contribuir ( $a s u$ ) /no solo á su/ servicio y obsequio, sino tambien á sus tareas, (siempre, sin desaprovechar) /no/ desaprovechando oportunidad de ayudarlas (a ellas) en cuanto lo permitan las circunstancias, el tiempo y ¿mi propia salud? o y me ocurran especies ó noticias que crea propias para los fines de /(esa)/ (nuestra) la Sociedad.

Acompaño á los libros que /envia a V. E./ nuestra Academia de la Historia (envia a V. E.) el tomo primero del Diccionario español-latino-arabigo, impreso aqui baxo mi direccion, (a cuyo frente) al $=$ principio del= qual puse un discurso sobre la utilidad /del estudio/ de la lengua arabe (-iga) especialmente para los españoles, (cuya) consideración que me movio a dedicar a su cultivo / $2 \mathrm{r} / \operatorname{los}$ ratos (de mi juventud) que me dexaban libres /en la juventud/ los estudios y negocios de mi profesión, Quedo en remitir $=$ apenas salgan $=$ dos tomos $(q u e)$ restan/tes/ para complemento de la obra, $(y)$ que estan baxo la prensa.

La Carta de V. E. y su /nuevo/ (memoria) don han renovado (/en mi/) los afectos de mi gratitud a (los) sus anteriores favores (de V.E., afirmándome cada vez más) y la estimacion y amistad /que siempre profese/ =á su recomendable= persona, cuya vida pido á Nuestro Señor guarde dilatados y felices años. Madrid, 24 de mayo de 1787. Excmo. Sr. Benjamín Franklin.

Las cartas de Flores y Campomanes fueron enviadas a Franklin por W. Carmichael el 22 de junio de 1787 (Benjamin Franklin Papers. American Philosophical Society. Hays Calendar. Part 9, Section II (1787-1789), XXXV, 84). La primera carta de Flores a Franklin del 18 de mayo de 1787 está inventariada como XXXV, 63 y la de Campomanes como XXXV, 68. 
Ramón de Guevara Vasconcelos. Se decidió, pues, poner de nuevo a prueba sus reconocidas dotes de truchimán para traducir aquel artículo de las Transactions of the American Philosophical Society, a fin de que, tras su lectura, la docta Casa pudiera enterarse finalmente de lo que decía el erudito francés y responderle como debía. Así es como se lee en las actas del mismo 30 de marzo, escritas por el mismo Guevara, lo siguiente:

La Academia acordó que yo traduzca la memoria tocante al descubrimiento de las Indias y que se lea en la Academia para poder contestar con conocimiento, viendo lo que sobre este asunto dicen Gonzalo Fernández de Obviedo, Antonio de Herrera y el Dr. Robertson, que no hace grande aprecio del alemán que se supone haber suministrado a Christobal Colón las noticias en que fundó su empresa para el descubrimiento del Nuevo Mundo, hecho de orden de los Reyes Católicos Don Fernando y $\mathrm{D}^{\mathrm{a}}$ Isabel; bien entendido que esta noticia en nada deroga a los derechos de la Corona, ora $^{46}$ fuese Cristóval Colón autor de la idea, ora la tomase de otro, juntándose lo demás que hubiere en la Academia sobre este asunto, para que se le pueda dirigir un discurso raciocinado, escrito con aquella exactitud y pureza que corresponden a nuestra crítica y obligación de Cronista de Indias.

No extraña, sobre todo procediendo de la pluma de Ramón de Guevara, que el inevitable Robertson tornara a ser considerado un cronista de la talla y fiabilidad de Oviedo y Herrera. Lo que sí llama la atención es que el académico se mostrase únicamente preocupado por preservar los derechos de la Corona de España a las Indias: en definitivas cuentas, que la idea descubridora partiera de Colón o de algún otro le importaba un ardite. También sorprende que no se dé nombre a este alemán exhumado por Mr. Otto y que no era otro, según veremos, que el famoso Martín Behaim. Ya G. B. Riccioli ${ }^{47}$ y J. Frid. Stuvenius, ${ }^{48}$ habían atribuido al bohemio la gloria de

46 El escribano, quizá el mismo Guevara, escribió "ahora”, después puso una "h" sobre el renglón ("ahora") y por fin tachó atinadamente la "a-".

47 "Christophorus Columbus, ex Palestrella stirpe Placentina oriundus et postea Liguriae incola, cum prius in Madeira insula, ubi conficiendis ac delineandis chartis Geographicis vacabat, sive suopte ingenio, ut erat vir Astronomiae, Cosmographiae et Physicies gnarus, siue indicio habito à Martino Bohemo, aut, ut Hispani dictitant, ab Alphonso Sanchez de Huelva nauclero, qui forte inciderat in insulam postea Dominicam dictam, cogitasset de nauigatione in Indiam Occidentalem..." (Geographiae et Hydrographiae reformatae libri duodecim auctore Reu. P. Io. Baptista Ricciolio Ferrariensi Societatis Iesu, Bononiae, ex Typographia Haeredis Victorij Benatij, 1661, III 22, pág. 92 b).

48 De uero noui orbis inuentore [Sobre el verdadero descubridor del Nuevo Mundo] Francfurt, 1714, folleto que no está en nuestra Biblioteca Nacional y que conozco por W. Robertson, Historia de América, Lib. de J. Oliveres y Gavarro, Barcelona, 1822, pág. 320. En esta Nota XVII aborda Robertson el problema del piloto anónimo, una fábula que considera nacida "por el interesillo de la gloria nacional" (pág. 318). Lo mismo se aseguraba en la Colección de viajes de Pedro Vander Aa (según Cristóbal Cladera, Investigaciones históricas sobre los principales descubrimientos de los españoles en el mar Océano en el siglo XV. y principios del XVI., en respuesta á la Memoria de Mr. Otto Sobre el verdadero Descubridor de América, Madrid, 1795, págs. 176ss.). 
haber realizado el primer viaje al Nuevo Mundo, sin alegar una sola prueba en demostración de su aserto; ésta era la teoría que volvía a defender Mr. Otto, pero basándose en otros testimonios. En cualquier caso, los académicos no tuvieron que aguardar mucho a satisfacer su curiosidad. Gracias a la diligencia de Guevara, el 11 de mayo de 1787 se revelaron por fin los secretos del sumario y los reparos que a los asertos de Otto formulaba nuestro anglófono español.

11 de mayo de 1787.

Leí la traducción del Discurso de Mr. Otto sobre el primer descubridor de América, que él pretende haber sido Martín Behem de Nieremberg en 1485, inserto en el tomo $2^{\circ}$ de las Transacciones de la Sociedad Filosófica de Filadelfia, que el Sr. Benjamin Franklin, nuestro Académico Honorario, ha regalado a la Academia; en cuya traducción (que he hecho por encargo de ésta) he añadido algunas notas marginales, remitiéndome en lo principal a la Memoria que presenté y leí el año de 77 . defendiendo haber sido el Almirante Colón el primero y verdadero descubridor, así de las islas como del continente del Nuevo Mundo, la qual también se traxo este día a la Academia; y en ella están, por vía de apéndice, los pasages íntegros a la letra de los principales Historiadores de Indias sobre este suceso.

Visto el informe de Guevara, el 18 de mayo de 1787 se redactó la respuesta oficial a la carta de Franklin, ${ }^{49}$ que fue la siguiente:

Excmo. Sr. Muy señor mío. Nuestra Academia Real de la Historia, a quien presenté el exemplar del tomo $2^{\circ}$ de las Transacciones o Memorias de la Sociedad Filosófica de Filadelfia, que con carta de 4 . de diciembre del año último se sirvió V.E. remitirme a este efecto, lo ha recibido con sumo aprecio, así por la ilustre mano de donde viene como por ver los tempranos y sazonados frutos de ese cuerpo, cuyo dignísimo presidente es V. E.

Entre ellos reconocerá con especial diligencia la Disertación de Mr. Otto sobre el primer descubridor de las Indias Occidentales, punto no menos importante para España que para el Nuevo Mundo, y sobre el qual hay en la Academia trabajos anteriores a éste y posteriores a la Historia de América escrita por el Dr Robertson, en defensa de haberlo sido el Almirante Don Christóbal Colón tanto de las Indias como del Continente de ese Emisferio, según refieren unánimente los historiadores más fidedignos y coetáneos a aquel suceso memorable, así nacionales como portugueses y extrangeros, siendo consiguientemente necesarios para contrarrestar esta aserción y posesión documentos muy auténticos y testimonios bien antiguos, positivos y termi-

49 Juzgo de cierto interés dar los nombres de los académicos asistentes a la sesión: el director Pedro Rodríguez Campomanes. Antonio Matheos Murillo., censor Felipe García Samaniego. Tomás Sánchez. Josef de Guevara. Casimiro Gómez Ortega. Antonio Capmany. Tomás López. Joseph Ruiz de Celada. Ignacio López de Ayala. Francisco Javier de Santiago Palomares. Miguel de Manuel y Rodríguez. Pedro Varela y Ulloa. Pe Joseph Banqueri. Pe Francisco Cañes. José de Vargas Ponce. Pedro Jacinto de Álava. Pe Montejo. Pe Isidoro Estébanez. Guevara junior (Ramón de Guevara), por el señor secretario (Joseph Miguel de Flores). 
nantes. Si hecho examen maduro e imparcial del citado discurso resultare alguna cosa nueva o importante sobre el asunto, cuidaré de trasladarla a noticia de V. E. como tan interesado en todo lo relativo a un país, de que es muy principal ornamento,

Entre tanto me encarga la Academia dé a V. E. las más expresivas gracias por la fineza de su memoria; en correspondencia con la qual me previene dirigirle, como lo hago, algunas de las obras que tiene publicadas, quedando en executar lo mismo con qualesquiera otras de las que salieren a luz y parezcan dignas de su curiosidad.

Celebro mucho esta coyuntura de ofrecer mi respetuosa atención a la obediencia de V. E., rogando a Dios guarde su vida muchos años para bien y lustre de su patria. Madrid, 18 de mayo de 1787. Exmo. Sr. Besa las manos de V.E. su más atento y seguro servidor Don Joseph Miguel de Flores.

Excmo. Sr. Benjamin Franklin

Esta segunda carta puso punto y final a la relación de la Academia con Franklin, que falleció poco después el 17 de abril de 1790. La verdad es que, a pesar de su ocasional y efímera correspondencia con Aranda y Campomanes, no muy fructífera por lo demás, las reservas mentales que albergaba Franklin respecto a España no se disiparon jamás. El gran hombre, un prodigio de versatilidad y de inteligencia, murió sin haber depositado gran confianza en la Corte española, cuya excesiva lentitud deploró con ocasión de la firma del tratado bilateral que se fraguaba en $1786:{ }^{50}$ por ello aconsejó dar largas a la firma, hasta que accediera al trono un nuevo rey con nuevas ideas o subieran al poder nuevos ministros con diferentes puntos de vista.

En cambio, algunos logros de la ciencia española merecieron esporádicamente la aprobación del sabio norteamericano. Así sucedió con el "muy erudito" libro sobre las antiguas monedas samaritanas (De nummis Hebraeo-Samaritanis. Dissertatio isagogica ad tractatum de Phenicum nummis quos incognitos uocant, Valencia, 1781), ${ }^{51}$ un volumen que

50 Carta a Charles Pettit del 10 de octubre de 1786 (WBF IX, pags. 544-545): "I should therefore rather advise Procrastination...., for Time may produce a new King with new Ideas, or new Ministers with different Views".

51 Es quizá el libro de Pérez Bayer que W. Carmichael envió el 4 de abril de 1785 a Franklin (Benjamin Franklin Papers. American Philosophical Society. Hays Calendar. Part 8, XXXIII, 69). La obra alabada por Franklin fue muy criticada en España, hasta el punto de que se publicó contra ella un folleto anónimo. Nicolás de Azara se quejó de tamaña vileza en una carta a Juan Bautista Muñoz, escrita en Roma el 17 de enero de 1787: "He dado un repaso al papel que vuestra merced me incluye contra las medallas samaritanas de nuestro Señor Bayer. En verdad el anónimo es pobre cosa, y lo peor que en aquel género podía producir. Quando se sintiera con fuerzas para impugnar robustamente el sistema del Señor Bayer, por qué no hacerlo a cara descubierta? No es ningún delito ser uno de diferente opinión de un Autor en materias de pura literatura, pero el contrabando acomoda más a ciertas gentes que no quieren correr el riesgo de medir sus fuerzas con quien interiormente se conocen inferiores, y se aventuran a gravámenes con el salvoconducto de la máscara" (Real Academia de la Historia, Colección Muñoz, tomo 3 (9/4781), ff. 178r-178v). En su defensa Pérez Bayer escribió las Nummorum HebraeoSaramaritanorum Vindiciae (Valencia, 1790). 
Franklin, a su vez, regaló el 9 de marzo de 1790, poco antes de morir, a la biblioteca del Colegio que regentaba en Filadelfia el reverendo Ezra Stiles. ${ }^{52}$ Ésta fue la mejor prueba de que no se habían cortado, ni mucho menos, los lazos eruditos entre España y los flamantes Estados Unidos y de que proseguía constante un cierto intercambio de libros. Ahora bien, el autor del tratado en cuestión no fue otro que Francisco Pérez Bayer (1711-1794), director durante algún tiempo de la Biblioteca Real y canónigo de Valencia. Y ocurre pensar que detrás de la traducción del Salustio hecha por el infante Don Gabriel se encontrase también Pérez Bayer, quien contribuyó asimismo a la corrección de la Bibliotheca Hispana Noua. Por tanto, tres de los libros que interesaron a Franklin aparecen ligados con la figura del gran erudito valenciano, una de las figuras más notables del siglo XVIII español, que hubo de ser el inspirador de la idea de entablar desde España correspondencia con el sabio estadounidense, unas veces por propia iniciativa, otras a través de W. Carmichael. Y fue Pérez Bayer, en definitiva, quien apoyó en la Corte a Juan Bautista Muñoz para que éste recibiera el título de Cosmógrafo Mayor de Indias. ${ }^{53}$

Es lástima que no llegasen a cuajar logros más sustanciosos. Sin embargo, en un punto es visible, a mi juicio, la huella que dejó Franklin en las futuras directrices de la diplomacia norteamericana. Una y otra vez insistió el famoso político en los desastres de todo tipo que ocasionaba un conflicto bélico; a su juicio, se podía y debía evitar la guerra y su inútil derramamiento de sangre por un medio más sencillo y económico: comprando al rival el territorio en debate. Así, según observó el 15 de diciembre de 1787, el emperador de Rusia alcanzaría mejor sus objetivos si, en vez de utilizar las armas, ofrecía al sultán la renta de la región turca cuya anexión pretendía, pero multiplicada por cien. ${ }^{54}$ Fiel a esta idea, Franklin propuso comprar a España al precio que fuera todos los derechos que tuviese a navegar por las aguas del Mississippi. ${ }^{55}$ Pues bien, este espíritu de transacción prevaleció en las compras de la Luisiana a Francia y, con otros matices, de la Florida a España.

52 "I send with this a very learned Book, as it seems to me, on the ancient Samaritan Coins, lately printed in Spain, and at least curious for the Beauty of the Impression. Please to accept it for your College Library" (X, pág. 83).

53 Así lo supuso acertadamente Ballesteros Beretta, A.: "Don Juan Bautista Muñoz...”, Revista de Indias, 3, págs. 8-9.

54 Fragmento de carta sin destinatario en WBF IX, pág. 625.

55 Carta a John Jay (Passy, 2 de octubre de 1780: ibídem, VIII, pág. 144). 


\section{Colón, destronado de su gloria: Martín Behaim, descubridor de América}

Pero pasemos ya a examinar el artículo en cuestión de las Transactions, intitulado A Letter from MR. OTTO to DR. FRANKLIN, with a Memoir on the Discovery of America, ${ }^{56}$ no sin antes presentar, como parece obligado, una sucinta biografía de su autor. El chevalier Luis-Guillermo Otto nació en Baden en el seno de una familia protestante alemana (1754). Tras estudiar en la Universidad de Estrasburgo, pasó al servicio del chevalier de la Luzerne, a quien acompañó como secretario cuando su patrono desempeñó una misión diplomática como ministro de Francia en Estados Unidos (1779-1784). En agosto de 1785 volvió Otto a Filadelfia como chargé d'affaires de Luis XVI ante el Congreso, puesto que desempeñó hasta 1791. Incorporado al ministerio de Asuntos Exteriores a su vuelta a París (1792), sufrió prisión durante el período revolucionario (1794). Con el imperio cambió su suerte, ya que Napoleón lo nombró conde de Mosloy, embajador en Viena (1810-1813) y consejero de Estado. Tras un sabio intervalo de acercamiento a los Borbones durante el reinado de Luis XVIII, Otto cometió la imprudencia de unirse a Napoleón durante la aventura de los Cien Días. Murió en Calais en 1817, privado de cargos oficiales.

El problema discutido por Otto y cuya solución creyó haber encontrado tras la lectura de algunas crónicas españolas y alemanas fue de nuevo la posibilidad de un predescubrimiento de América, realizado esta vez por un cartógrafo tudesco de cuyas noticias se habría servido Colón en provecho propio años después; no cabe descartar, en consecuencia, que el alsaciano, por muy fiel servidor de Francia que fuese, pretendiera con su artículo exhumar glorias de ilustres antepasados alemanes. El punto de arranque de su estudio lo constituye el famoso pasaje del Inca Garcilaso sobre Alonso Sánchez de Huelva: "il assure que ce navigateur [Colón] avoit été instruit de l'existence d'un autre continent par Alonzo Sanchez de Huelva, qui faisant route pour les Canaries avoit été poussé aux Antilles par un coup de vent; mais qu'il avoit sur tout tiré grand parti des informations d'un cele-

56 Transactions of the American Philosophical Society, II (1786) 263-284 (n. ${ }^{\text {o } 35), ~ p u b l i c a d o ~}$ en inglés y en francés. La carta de Otto a Franklin está fechada el primero de abril de 1786; no era la primera vez que Otto se dirigía a Franklin, pues ya le dio la bienvenida a los Estados Unidos el 28 de septiembre de 1785 (Benjamin Franklin Papers. American Philosophical Society. Hays Calendar. Part 9, Section I (1783-1786, XXXIII, 201). Ni la carta de Franklin a la Academia ni este volumen de las Transactions se conservan actualmente en la Biblioteca de la Academia de la Historia. 
bre Geographe nommé Martin Behenira". A Otto no le costó gran esfuerzo identificar a este Martín Behenira con Martín Behem (esto es, Martín Behaim) y, a partir de ahí, atribuir a Behaim el descubrimiento de América basándose en otro documento coetáneo, la Chronica de Hartman Schedel, que en el año 1485 registra la larga navegación que hicieron allende el ecuador Jacobus Canus y Martinus Bohemus. Nada habría que objetar a esa conclusión si no fuera por dos hechos: que Garcilaso no cita en el capítulo antedicho a Martín "Behenira" y que el viaje de Diego Cão y Behaim se dirigió a Guinea y no a América. Los otros textos que aduce Otto en apoyo de su tesis tampoco son probantes: Pedro Mattei no se refiere a un viaje transatlántico, sino a la navegación africana, y Cristóbal Keller o Cellarius (1638-1707) es un escritor demasiado tardío para ser digno de crédito en sus afirmaciones. Los documentos "auténticos" conservados en Nuremberg que atestiguarían un viaje de Behaim al Estrecho de Magallanes en 1484, por falsos, no merecen siquiera discusión, aunque bien es verdad que, según se dice (Oviedo, Benzoni), Magallanes mostró tal estrecho a Carlos I en un mapa hecho por Behaim (de haber existido ese mapa, su autor pudo haber sido J. Schoener). Una prueba más: en el globo hecho por Behaim en 1492, según Otto, aparecen delineadas las costas del Brasil y los aledaños del Estrecho de Magallanes; es que en una de sus navegaciones a Guinea, Behaim se habría visto arrastrado por una tempestad a Pernambuco y de ahí a la Guayana; mas es preciso tener buenas dotes de fantasía para reconocer esas tierras en la nebulosa de una cartografía imaginaria. Por fin, así como el buen epigrama termina clavando un aguijón, el revolucionario artículo de Otto remata con pullas y anatemas. El silencio de los historiadores portugueses y españoles sobre el bohemio se debería simplemente a la supina ignorancia ibérica: en cuanto a Portugal, "toute la nation, à l'exception du souverain, étoit plongée dans la plus grand ignorance... Et si ce peuple a fait les decouvertes les plus importantes, il en faut chercher le motif dans sa cupidité, et non dans son desir de s'instruire"; por lo que toca a los españoles, "n'étoient pas plus instruits, avant que Charlesquint eut amené à Madrid des savans de Flandre et d'Allemagne". La gloria de Behaim, en consecuencia, no debería ser indiferente al patriota americano, a quien se exhorta de todo corazón a honrar a los descubridores de su tierra:

Pourquoi Behem, Christophe Colomb et Vespuce ne meriteroient'-ils pas des statues sur les places publiques des villes Américaines ? Ces monumens precieux transmettroient à la posterité la reconnoissance que doivent inspirer les noms de ces bienfai- 
teurs du genre humain. Sans le savoir, ils ont jetté les fondemens du bonheur de plusieurs millions d'habitans.

¡Qué diferencia entre aquellos elogios ditirámbicos y los insultos soeces y desatinados que se propinan a Colón en la actualidad!

\section{Dos lecturas opuestas del artículo de Otto: Guevara y Muñoz}

Como se ha visto, durante largo tiempo no apareció en la Península Ibérica ninguna obra importante en torno a los orígenes de la dominación española en América. Sólo se escribieron sobre este tema en el mejor de los casos vagas obras generales o en el peor, refritos - como el de Estradaque avergonzaron a la propia Academia. Sus miembros, por su parte, se desentendieron de la tarea que les incumbía. El revulsivo les llegó en forma de velada reprimenda, cuando el 17 de junio de 1779 el rey encomendó a Juan Bautista Muñoz ${ }^{57}$ la tarea oficial de escribir la Historia del Nuevo Mundo. El malestar corporativo tardó en manifestarse, pero estalló cuando Muñoz, a punto de terminar el primer volumen de su obra, solicitó que se le facilitase el acceso a los documentos guardados en la Academia de la Historia. El escozor por el desaire sufrido se hizo patente en la sesión del 10 de octubre de 1788. A la Academia, como cronista de las Indias, "no le es lícito mirar con indiferencia que se haia fiado su desempeño a una persona particular que ni aun es del número de sus individuos, encargándole, con desaire suyo, las más esenciales y preciosas funciones de su empleo". Menos mal que, en vez del improperio, se impuso la razón. La Academia eligió la vía del compromiso y, para conciliar el honor y el interés de Muñoz con "el decoro y justa consideración" que a ella se le debía, pidió acoger en su seno a Muñoz para que en adelante, y ya como numerario de la Casa, trabajase al menos bajo su dirección. La futura historia habría de comenzar "por una descripción geográfica de aquellas dilatadas regiones", sin duda para no suscitar las presumibles y justas quejas de uno de sus individuos, Antonio Alcedo y Herrera (1735-1812), que ya por entonces preparaba el famoso Diccionario geográfico-histórico de las Indias Occi-

57 Interesan los siguientes artículos de Ballesteros Beretta, A.: "Don Juan Bautista Muñoz. Dos facetas científicas", Revista de Indias, Año II, 3, págs. 5ss.; "Juan Bautista Muñoz: la creación del Archivo de Indias", Revista de Indias, Año II, 4, Madrid, 1941, págs. 55-95, págs. 55ss. y "Don Juan Bautista Muñoz. La Historia del Nuevo Mundo", Revista de Indias, Año III, 10, págs. 589-591, reproducidos parcialmente en el Catálogo de la Colección de don Juan Bautista Muñoz, 3 tomos, Editorial Atlas, Madrid, 1954, I, págs. IX-XLVIII. 
dentales ó América que se habría de publicar en Madrid pocos años más tarde (1786-1789). De todas formas, no cabe duda de que algunos pensaban que a un Muñoz académico se le podría atar muy corto. Pero el rey hizo oídos sordos a la petición, y el 23 de septiembre de 1788 ordenó al cronista que prosiguiese con su Historia del Nuevo Mundo y a la Academia que lo hiciese miembro de su Corporación.

No es cuestión de hablar aquí de la encarnizada lucha que sostuvo Muñoz contra una facción cerril de la Corporación, lucha que ha sido bien descrita por A. Ballesteros. De aquella polémica sólo nos interesa aquí la censura particular al manuscrito original de Muñoz, escrita el 10 de noviembre de 1792, que el 21 de octubre siguiente el académico José de Guevara Vasconcelos, anticuario en la Casa desde 1775, presentó a la consideración de sus sabios colegas. A Guevara lo soliviantó sin duda la idea de que quien se llevara los laureles de haber escrito la Historia del Nuevo Mundo fuese Muñoz y no su pariente - ihermano? — ${ }^{58}$ Ramón, el frustrado traductor de Robertson, que, para avivar el dolor y el resentimiento familiar, había muerto hacía poco (1790). Por esta razón cualquier argumento le pareció válido a J. Guevara a la hora de atacar con saña la buena fama científica del cronista de Indias. Antes la Academia había despachado con cierta displicencia el artículo de Otto; ahora Guevara le daba la razón:

\begin{abstract}
Martín de Bohemia tiene a su favor, además de los documentos de Nuremberg, historiadores del mismo tiempo, confirmados por los coetáneos españoles y otros posteriores de las demás naciones. En 1493 se imprimió en Robuger la Crónica de Hernán Schedl, en que se asegura que Behem descubrió antes que Colón la América, y esta noticia la insinuó Gómara, y los comentadores de Eneas Silvio insertaron el texto de Schedl. Una opinión, apoyada por estos documentos coetáneos, que quita a Colón la gloria del descubrimiento y a los reyes de España el derecho a las Indias Occidentales, me parece que no ha debido tratarse con tanta ligereza, cuando es muy difícil que el lector pueda por sí mismo dar solución a tan grave dificultad. ${ }^{59}$
\end{abstract}

La mala fe salta a la vista. Donde antes no había problemas, ahora hasta los dedos se volvían huéspedes. En 1787 el incógnito descubrimiento de Behaim no había supuesto merma alguna a los justos títulos de la Corona española a la posesión de las Indias; en 1792, al cumplirse el tercer centenario, ese mismo nebuloso viaje privaba al rey de España de todo

58 Así lo supuso Ballesteros Beretta, A.: "Don Juan Bautista Muñoz: La Historia...”, Revista de Indias, Año III, 10, pág. 622.

59 Lo publicó C. Fernández Duro en el Boletín de la Real Academia de la Historia, 42, págs. 24-25. 
derecho a América: morrocotudo cambio de ideas que entrañaba un verdadero peligro estando, como se estaba, en plena era revolucionaria. Por otra parte, en un puñado de líneas Guevara cometió no pocos errores, llamando Hernán a Hartman, Robuger a Nuremberg y hablando de "los comentadores de Eneas Silvio" cuando lo que había escrito Otto había sido "los editores de Eneas Silvio" ("the publishers of his works").

El palmetazo que Muñoz, en su respuesta, propinó a Guevara al abordar este punto fue sonado. Empezó por afearle el haberse engalanado con los "trapos feos y mal zurcidos" de un académico de Filadelfia (no lo era Otto), "ocultando el dueño de ellos y la mano por donde le han venido". Siguió afirmando que no había "ni un solo autor o documento coetáneo que eximiese de la nota de imaginario el mapa de Behem en la parte del Océano occidental, donde pone tierras por fantasía". Tachó de falso el "papel mojado de los archivos de Nuremberga". De nada valía el testimonio de los autores coetáneos aducidos por Guevara, pues Schedel y Mattei se referían a las navegaciones de los portugueses por la costa de África, y Gómara no había incurrido en el "disparate" que le atribuía desatinadamente el académico. "Buenos andarían los derechos de la nación si se pusieran en manos del Sr. Guevara", concluyó irónico Muñoz, que insinuó veladamente que su censor no se aprovechaba directamente de Otto, "sino de los apuntamientos de un amiguito, según oigo y lo indican las equivocaciones de Hernán por Hartman y de comentadores por copiantes [en este punto se equivoca Muñoz] de Eneas Silvio". ${ }^{60}$ Contra qué persona se dirigían los dardos de Muñoz lo ignoro; pero el artículo de Otto lo había conocido de manera directa, o al menos a través de las conversaciones con Ramón Guevara. En cualquier caso, el pretendido Aristarco debió de quedar bien escaldado de su repulsa a Muñoz: ningún académico secundó un rechazo nacido del rencor. Curiosamente, tampoco quedó dañado su prestigio como crítico. En recompensa de su incompetencia, la Academia lo nombró archivero el 14 de marzo de 1794 y censor el 29 de noviembre de 1799, cargos que siguió desempeñando hasta su muerte (1 de noviembre de 1804).

\section{Se dispara la polémica: C. Cladera contra Otto}

La demoledora contestación de Muñoz a Guevara, que refutó sucintamente el meollo de la vibrante y seductora tesis del chevalier Otto, no salió

60 Ibídem, págs. 45-46. 
jamás a la luz pública y, en consecuencia, durmió un plácido sueño en los eruditos anaqueles de la Academia. Ahora bien, como España es país de reacciones a destiempo y plantel de frutos tardíos, no es de extrañar que Otto encontrase a los pocos años un impugnador inesperado en la persona de un ilustrado clerigo mallorquín, Cristóbal Cladera (1760-1816) ${ }^{61}$ Sin duda, alguien en las alturas (quizá su correligionario Campomanes o tal vez, mejor, Floridablanca) juzgó que no se podía dejar que corriesen impunemente opiniones que podían socavar los cimientos de un imperio que empezaba a cuartearse. Lo que extraña es lo tardío de la réplica.

El caso fue que Cladera, beneficiado en tiempos de la Iglesia de Sevilla ${ }^{62}$ y a la sazón tesorero de la de Mallorca, salió a defender como un caballero andante la fama de los navegantes portugueses y españoles contra las ideas tanto de Otto como de Forster y otros, "que desde tres siglos se han empeñado en obscurecerlos, ó en disminuir el mérito de aquellos Héroes tan superiores à quantos presentan las Historias". La polémica obra, publicada en 1795, fue dedicada a don Manuel de Godoy, duque de la Alcudia, entonces en la cúspide de su fama, a quien se enlazó en aduladora genealogía con la casa real de Portugal y las familias de los grandes descubridores ibéricos (Colón, Tristán de Acuña, Cabral, Vasco de Gama y Magallanes). El libro es hoy una antigualla erudita; ${ }^{63}$ pero hay que reconocer que no faltaron a Cladera ni laboriosidad ni diligencia a la hora de recopilar información y documentos. En efecto, el sacerdote consiguió una copia del globo de Behaim, que describió prolijamente en págs. 184ss. no sin adjuntar una copia del Atlántico conocido y desconocido que figura en el globo, según un grabado hecho por Chr. T. de Murr en 1778; se hizo traer obras inéditas de la Academia de Ciencias de Lisboa; revolvió manuscritos en la Biblioteca Real de Madrid (la crónica de Andrés Bernal o Bernáldez, la carta impresa de Colón), se procuró copias de roteros (así, del diario de navegación de Francisco Alvo) y consultó varios mapas (entre ellos, los de Vallseca y Antonio Ortiz). El grueso del libro lo forman la refutación de Forster y sobre todo de Otto, los dos puntos que Cladera sometió a examen:

61 Da de él un breve resumen biográfico en la Enciclopedia Espasa, XIII, pág. 596 b.

$62 \mathrm{He}$ intentado en vano buscar noticias sobre Cladera en los archivos hispalenses. Desde luego no fue prebendado de la catedral (no figura en el Libro de entradas correspondiente [Archivo de la Catedral de Sevilla, 07436]).

63 Investigaciones históricas sobre los principales descubrimientos de los españoles en el mar Océano en el siglo XV. y principios del XVI., en respuesta á la Memoria de Mr. Otto Sobre el verdadero Descubridor de América, por don Antonio Espinosa, calle del Espejo, Madrid, 1795, 218 págs. 
a) Viajes de Herjolf y su hijo Biorn a Groenlandia (teoría de Forster). El viaje, de haberse hecho en realidad, cayó en el olvido: "luego no se sabía antes del año 1492 que existiera la América; luego en nada puede perjudicar a Colón la expedición del comerciante islandés" (págs. VIII-IX).

b) Viaje de Martín Behaim al Brasil en 1484, en el que el alemán habría llegado hasta el Estrecho de Magallanes, poniendo a sus habitantes el nombre de patagones (teoría de Otto). No, replica Cladera: el Brasil, que no figura en el globo de Behaim, fue descubierto por Cabral de un modo fortuito. Colón tampoco recibió de Behaim un derrotero de su viaje, ya que el primer almirante de las Indias no fue en demanda del estrecho allí donde debiera haberlo buscado de haberse guiado por el supuesto mapa del estrecho de Behaim (discusión en págs. 87ss.). En resumidas cuentas, Otto malentendió sus fuentes o sacó de ellas conclusiones inaceptables: así, además de no haber sabido interpretar de manera correcta la crónica de Schedel, su incompetencia le hizo confundir el globo de Behaim con el de Schoener, despeñándolo en teorías inaceptables. Por último, Otto incurrió en un defecto común a otros coterráneos suyos: tachar a portugueses y españoles de zafios e incultos. Dolido en lo más profundo de su alma, Cladera se defendió a su vez de una manera muy española: haciendo una larga e inoportuna apología de la ciencia patria (págs. 149ss.).

Cladera, cordial enemigo de Moratín, no era ni mucho menos un autor novel, aunque había sobresalido sobre todo como traductor prolífico (en 1785 publicó nada menos que cuatro volúmenes), a veces en perjuicio de la pureza de su castellano. Su libro más personal, a fin de cuentas, fue su estudio sobre los descubrimientos. He aquí la lista de su extensa producción literaria como truchimán:

I. El Juicio Final (Madrid, 1785, en la imprenta de don Joseph Doblado), traducción del poema de Edward Young The Last Day dedicada a otro mallorquín, don Antonio Barceló, teniente general de la armada, comandante del bloqueo de Gibraltar (el promotor de las "lanchas cañoneras") y de las dos últimas expediciones contra Argel, a quien Cladera describió como el perfecto héroe cristiano.

II. Reflexiones sobre las ventajas que resultan del comercio al Estado, por Joseph Addison, Primer Secretario de Estado de la Gran Bretaña. Traducidas del inglés por D. Cristóbal Cladera (Madrid, 1785, Joachín Ibarra).

III. Tratado sobre las violencias publicas y particulares por Maximiliano Murena, jurisconsulto napolitano. Traducido del italiano al francés; y de este idioma al castellano por D. Cristóval Cladera (Madrid, 1785, Plácido Barco). En el prólogo Cladera, probablemente sin haber leído el Leviatán, criticó las tesis de Hobbes, que "era Atheo, y sostenía los principios de Moral, y de Política los más peligrosos" (págs. VIII-IX).

IV. Tratado sobre las obligaciones del juez, también de M. Murena y en la misma imprenta de Plácido Barco. En el breve prólogo ensalzó al autor, pero sin privarse de señalar dos errores que, su a juicio, había cometido. 
V. Discurso historico critico y politico sobre los primeros ministros, los consejeros intimos, y los favoritos de los soberanos. Uno de los que sobre Tácito escribio Tomas Gordon, (Madrid, 1787, Imprenta Real). En el prefacio festejó al conde de Floridablanca: "Gloriemonos los españoles, pues el Ministerio que nuestro sabio Monarca ha escogido, mueve esta gran máquina de manera, que en breve la hará tocar los extremos de la pública prosperidad".

VI. De juris legumque scientiae praestantia seu de illius ad Reipublicae conservationem necessitate exercitatio academica, quam in publica legum disputatione erat ipse habiturus in Orcellensi Athenaeo, anejo al Discurso anterior. Es un pequeño folleto escrito en buen latín, ensalzando el Derecho y, de paso, execrando la barbarie extrema de los habitantes de Cuzco "antes de que se instruyesen por el trato con los españoles" ${ }^{64}$ ¿una pulla envenenada a Les Incas, ou la destruction de l'empire du Perou de Juan Francisco Marmontel, publicado en 1778, una novela sobre la conquista de las Indias por los españoles?

VII. Espíritu de los mejores diarios literarios que se publican en Europa, ${ }^{65}$ la revista que editó, aprovechando sus dotes de traductor, de 1787 a 1791 bajo la protección del conde de Floridablanca. Es la obra con la que Cladera se hizo un nombre y por la que hoy se le conoce. ${ }^{66}$

VIII. Diccionario Universal de Física de Brisson (1796-1802), empeño importante por haber incorporado a nuestro idioma la terminología científica europea.

Hombre de espíritu inquieto y liberal, pero nada revolucionario, socio temprano de la Sociedad Económica de Madrid, Cladera fue firmante de la Constitución de Bayona y jefe de la tercera división del Ministerio del Interior del rey José I. Expulsado de España con los franceses, regresó a su

64 La cita sobre los incas del Cuzco (emparejados con los africanos y los habitantes salvajes de las islas de la India) se encuentra en págs. 109-110: "è re tamen mea esse arbitror, Cusci civium mores ipsorumque religionem, antequam Hispanorum comercio erudirentur, vobis qua possim brevitate enarrare, non quod existimem, quamplurima vestrum haec esse ignota, sed quod vix credi possit homines, summi $\mathrm{a}<\mathrm{d}>$ Dei imaginem eformatos, adeo infandis criminibus fuisse pollutos". La única solución para remediar tantos males y errores fue el Derecho, según Cladera (y no la religión, cosa curiosa). En su denuncia de la bestialidad incaica el mallorquín se basó en los Comentarios del Inca Garcilaso (I 12). Este folleto latino, que manejo en el ejemplar de la Biblioteca Universitaria de Sevilla (A/109/107/6-7), no está registrado en la excelente Bibliografía de autores españoles del siglo XVIII de F. Aguilar Piñal (CSIC, Madrid, 1983, II, pág. 420).

65 Sobre su estancia en Cádiz ver Sureda i Blanes, Joseph: La formació de Cristófor Cladera (Cadis 1776-1785), Conferència pronunciada a Sa Pobla, la nit del 16 de gener de 1973, edició del Magnífic Ayuntament de Sa Pola, Mallorca, 1974.

66 Como periodista es citado siempre en el tomo XXXI. 1 (La época de la Ilustración. I. El Estado y la Cultura) de la Historia de España fundada por R. Menéndez Pidal (Espasa Calpe, Madrid, 1988). Y a estudiar su actividad como tal está dedicado el libro de Varela Hervías, E.: El Espíritu de los mejores diarios literarios que se publican en Europa (1787-1791), Madrid, 1966. Cladera jugó hábilmente con la amenaza de suspensión de la revista para ganarse suscriptores: así, en su número 152 (27 de octubre de 1788). Pero con la caída de Floridablanca y la subida al poder de Aranda la prohibición se hizo realidad. En la selección de artículos, normalmente extranjeros, que fue el Espíritu se encuentra la reseña del famoso libro The History of Mexico del jesuita F. J. Clavigero, publicada en el British Register (13 de octubre de 1788, págs. 458ss.). 
patria en 1814 por expresa autorización de Fernando VII. Hasta el último momento sorprende en él su extrema habilidad para navegar entre dos aguas, estando siempre a bien con el poder, sea cual fuese.

Tanto el artículo de Otto como la obra de Cladera merecieron el honor de ser citadas por Washington Irving en su biografía de Cristóbal Colón. ${ }^{67}$ En la actualidad la polémica, ya un tanto rancia, enseña sin embargo que la historiografía se mueve casi siempre en las mismas coordenadas: el colombinismo de hoy no es muy diferente al colombinismo de ayer y, por lo general, se siguen discutiendo cansinamente los mismos problemas, con diversos intereses nacionales en juego.

\section{Publicación de la Historia de América de W. Robertson}

La aparición del primer tomo del magno empeño de Muñoz (Madrid, $1793)^{68}$ marcó el fin de una era y el comienzo de otra. Fue lástima que su autor muriese muy pronto (1799), sin haber podido disfrutar del material que había recogido en tantos años de trabajo intenso. El americanismo, por un momento, pareció quedar desvalido, y en este momento de desorientación se trató de colmar el vacío con una obra ya envejecida.

Así fue como la Historia de América. Su autor Mr. Guillermo Robertson corrió finalmente de molde, pero no en la traducción de Ramón de Guevara, sino en la de don Félix Ramón de Alvarado y Velaustegui, precedida de una encomiástica dedicatoria al infante don Carlos Isidro de Borbón. El primer volumen fue publicado en la imprenta de Sancha en 1822, ocupando las XXVI eruditas "Notas é Ilustraciones" las páginas 301333. Por desgracia, la versión fue hecha del francés y no del inglés, a juzgar por transcripciones de nombres como "Tigre" (pág. 61), "Hydaspe" (pág. 305) y "Onesicrite" (pág. 113) en vez de Tigris, Hidaspes y Onesícrito, o por el delatador hecho de citar la obra de Hernando Colón como "Vie de Colomb" (passim) y el Somnum Scipionis ciceroniano como "Songe de Scipion" (pág. 308), etc. Mejor hubiera sido, a la vista de este pobre resultado, que hubiese salido a la luz en su momento la traducción académica.

Recibido el 15 de febrero de 2008

Aceptado el 14 de abril de 2008

67 La edición que empleo de The Life and Voyages of Christopher Columbus es la publicada en sus obras completas: The Works of Washington Irving, (P. F. Collier and Son), Nueva York, s.f., VII, pág. 265.

68 Abarca los años que van de 1492 a 1499 